\title{
Synthesis of Poly(propargyl esters) with Rhodium Catalysts and Their Characterization
}

\author{
Wei Zhang, Junichi Tabei, Masashi Shiotsuki, Toshio Masuda ( $\bowtie$ ) \\ Department of Polymer Chemistry, Graduate School of Engineering, Kyoto University, Katsura \\ Campus, Kyoto 615-8510, Japan \\ E-mail: masuda@adv.polym.kyoto-u.ac.jp; Fax: +81-75-383-2590
}

Received: 25 March 2006 / Accepted: 1 May 2006

Published online: 16 May 2006 - ( ) Springer-Verlag 2006

\section{Summary}

Propargyl esters $\left(\mathrm{HC} \equiv \mathrm{CCH}_{2} \mathrm{OC}(=\mathrm{O}) \mathrm{R} ; \mathbf{1}: \mathrm{R}={ }^{-} \mathrm{C}_{5} \mathrm{H}_{11}, \mathbf{2}: \mathrm{R}=\mathrm{CH}_{3}, \mathbf{3}: \mathrm{R}=\mathrm{CHBrCH}_{3}\right.$, 4: $\left.\mathrm{R}=\mathrm{C}_{6} \mathrm{H}_{5}, 5: \mathrm{R}=\mathrm{C}\left(\mathrm{C}_{6} \mathrm{H}_{5}\right)_{3}\right)$ were polymerized by using $(\mathrm{nbd}) \mathrm{Rh}^{+}\left(\eta^{6}-\mathrm{Ph}^{-}-\mathrm{B}^{-} \mathrm{Ph}_{3}\right)$ (nbd $=2,5$-norbornadiene) to produce poly $(\mathbf{1})-\operatorname{poly}(\mathbf{5})$ with molecular weights in the range of $M_{\mathrm{n}}=4,900-40,000$. Poly(1), poly(3) and poly(4) were readily soluble in common organic solvents such as toluene, THF and $\mathrm{CHCl}_{3}$, and poly(2) showed similar solubility behavior except that it was insoluble in THF. Poly(5) did not dissolve in any organic solvent. Poly(1) was yellow oil, while poly(2)-poly(5) were yellow solids. Poly(1)-poly(4) exhibited UV-vis absorptions in a range of 300-425 $\mathrm{nm}$, which are attributed to the conjugation of the main chain. All the polymers were thermally stable up to $150-200{ }^{\circ} \mathrm{C}$.

\section{Introduction}

Substituted polyacetylenes are well-known conjugated polymers, which display unique properties such as semiconductivity, high gas permeability, helix formation, and nonlinear optical properties [1,2]. Among a rich variety of these polymers, poly(propargyl esters) are a class of monosubstituted polyacetylenes, which show potential as humidity-sensitive materials [3-5]. The polymerization of propargyl esters was mainly carried out by Pd, Mo and W transition metal catalysts [3-8]. For example, propargyl acetate (2) and propargyl benzoate (4) were polymerized by using a Pd acetylide catalyst, $\mathrm{Pd}\left(\mathrm{PPh}_{3}\right)_{2}\left(\mathrm{C} \equiv \mathrm{CC}_{6} \mathrm{H}_{4} \mathrm{C} \equiv \mathrm{CH}\right)_{2}$, yielding soluble polymers with high molecular weights $\left(M_{\mathrm{n}}=15,000-21,000\right)$ in good yields (71-80\%) [7].

Since rhodium complexes are effective for the polymerization of monosubstituted acetylenes carrying polar functional groups, they are expected to catalyze the polymerization of propargyl esters as well. However, only a few propargyl esters bearing chiral pendant groups were polymerized by a zwitterionic Rh catalyst, (nbd) $\mathrm{Rh}^{+}\left(\eta^{6}-\mathrm{Ph}^{-} \mathrm{B}^{-} \mathrm{Ph}_{3}\right)$, to obtain helical polyacetylenes $[9,10]$. To the best of our knowledge, the polymerization of propargyl esters by $\mathrm{Rh}$ catalysts has not been investigated in details except that the polymerization of propargyl hexanoate (1) catalyzed by (nbd) $\mathrm{Rh}^{+}\left(\eta^{6}-\mathrm{Ph}-\mathrm{B}^{-} \mathrm{Ph}_{3}\right)$ was briefly communicated [9]. Thus it is 
interesting to examine the polymerization behavior of propargyl esters having aliphatic or aromatic groups by using Rh catalysts and to study the polymer properties.

This paper reports on the polymerization of propargyl esters (1-5) with $\mathrm{Rh}$ catalysts (Scheme 1). The effects of monomer concentration, polymerization temperature and solvents were examined in the polymerization of $\mathbf{1 - 5}$. The resulting polymers were characterized by ${ }^{1} \mathrm{H}$ NMR, IR and UV-vis, and their thermal stability was examined by TGA.
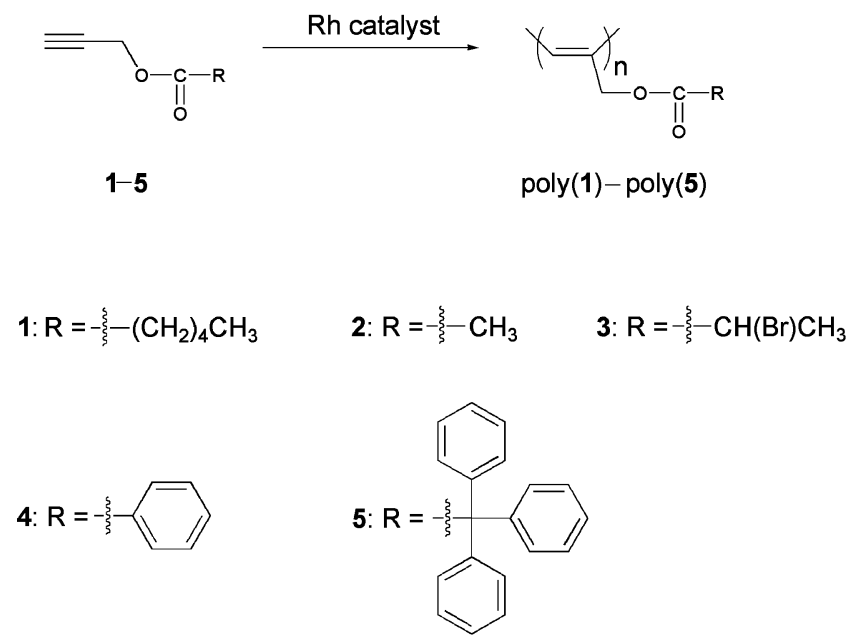

Scheme 1. Polymerization of monomers 1-5.

\section{Experimental}

\section{Measurements}

${ }^{1} \mathrm{H}$ and ${ }^{13} \mathrm{C}$ NMR spectra were recorded in chloroform- $d$ on a JEOL EX-400 spectrometer. Infrared spectra (IR) were measured using a JASCO FTIR-4100 spectrophotometer. The number- and weight-average molecular weights $\left(M_{\mathrm{n}}\right.$ and $M_{\mathrm{w}}$, respectively) of polymers were determined by gel permeation chromatography (GPC) on a Jasco Gulliver System (PU-980, CO-965, RI-930, and UV-1570) equipped with polystyrene gel columns (Shodex K804, K805, and J806), using tetrahydrofuran (THF) as an eluent at a flow rate of $1.0 \mathrm{~mL} / \mathrm{min}$, calibrated by polystyrene standards at $40{ }^{\circ} \mathrm{C}$. UV-vis spectra were measured on a Shimadzu UV-2200 spectrophotometer. Thermogravimetric analysis (TGA) was conducted on a Perkin-Elmer TGA thermal analyzer.

\section{Materials}

$\mathrm{WCl}_{6}$ (Aldrich), $\mathrm{MoCl}_{5}$ (Aldrich), $\mathrm{Ph}_{4} \mathrm{Sn}$ (TCI), and triethylamine $\left(\mathrm{Et}_{3} \mathrm{~N}\right)$ (Wako) were purchased and used without further purification. Monomers 2 (Wako) and 4 (Aldrich) were used after distillation under reduced pressure. Monomer 3 [11], [(nbd)RhCl $]_{2}$ (nbd = 2,5-norbornadiene) [12] and $(\mathrm{nbd}) \mathrm{Rh}^{+}\left(\eta^{6}-\mathrm{Ph}^{-} \mathrm{B}^{-} \mathrm{Ph}_{3}\right)$ [13] were synthesized according to the literature. Tetrabutyltin $\left(n-\mathrm{Bu}_{4} \mathrm{Sn}\right)$ and all the solvents for polymerization and monomer synthesis were purified by the standard methods. The 
reagents for monomer synthesis were commercially obtained and used without purification.

\section{Synthesis of Propargyl Hexanoate (1)}

Monomer 1 was synthesized according to the literature method [14]: Hexanoic acid (5.67 g, $48.9 \mathrm{mmol})$, 1-(3-(dimethylamino)propyl)-3-ethylcarbodiimide hydrochloride (EDC. $\mathrm{HCl})(10.3 \mathrm{~g}, 53.7 \mathrm{mmol})$, 4-(dimethylamino)pyridine (DMAP) (0.672 g, 6.0 mmol), and propargyl alcohol $(3.03 \mathrm{~g}, 53.7 \mathrm{mmol})$ in $90 \mathrm{~mL}$ of dry $\mathrm{CH}_{2} \mathrm{Cl}_{2}$ were stirred overnight. The mixture was filtered, and the filtrate was evaporated. The resulting oil was purified by silica gel column chromatography eluted with hexane to give colorless liquid in $72 \%$ yield. ${ }^{1} \mathrm{H}$ NMR (ppm): $0.90\left(\mathrm{t}, J=6.40 \mathrm{~Hz},-\mathrm{CH}_{3}, 3 \mathrm{H}\right)$, $1.33\left(\mathrm{~m},-\left(\mathrm{CH}_{2}\right)_{2}-\mathrm{CH}_{3}, 4 \mathrm{H}\right), 1.64\left(\mathrm{~m},-\mathrm{CH}_{2}-\left(\mathrm{CH}_{2}\right)_{2}-\mathrm{CH}_{3}, 2 \mathrm{H}\right), 2.33$ (t, $J=7.20 \mathrm{~Hz}$, $\left.\mathrm{O}_{2} \mathrm{C}-\mathrm{CH}_{2}-\mathrm{CH}_{2}, 2 \mathrm{H}\right), 2.51(\mathrm{~s}, \mathrm{H}-\mathrm{C} \equiv \mathrm{C}, 1 \mathrm{H}), 4.69\left(\mathrm{~s}, \mathrm{HC} \equiv \mathrm{C}-\mathrm{CH}_{2}-, 2 \mathrm{H}\right) .{ }^{13} \mathrm{C} \mathrm{NMR}$ (ppm): 13.71, 22.13, 24.34, 31.06, 33.77, 51.57, 74.59, 76.68, 172.76. IR $\left(\mathrm{CHCl}_{3}, \mathrm{~cm}^{-1}\right)$ : 3294, 2958, 2933, 2130, 1743. Anal. Calcd for $\mathrm{C}_{9} \mathrm{H}_{14} \mathrm{O}_{2}$ (154.2): C, 70.10; H, 9.15. Found: C, 70.07; H, 9.15.

\section{Synthesis of Propargyl Triphenylacetate (5)}

This compound was prepared following a procedure similar to that of monomer $\mathbf{1}$ by reacting triphenylacetic acid $(4.69 \mathrm{~g}, 16.3 \mathrm{mmol})$ with propargyl alcohol $(1.01 \mathrm{~g}, 17.9$ mmol). Purification of the crude product was carried out by silica gel column chromatography eluted with hexane/ethyl acetate $=10 / 1$ (volume ratio) to give a white solid in $83 \%$ yield. Melting point: $123-124{ }^{\circ} \mathrm{C}$. ${ }^{1} \mathrm{H}$ NMR (ppm): 2.39 (s, H-C $\equiv \mathrm{C}$, 1H), $4.74\left(\mathrm{~s},-\mathrm{CH}_{2}-, 2 \mathrm{H}\right), 7.14-7.26(\mathrm{~m}$, aromatic $\mathrm{H}, 15 \mathrm{H}) .{ }^{13} \mathrm{C} \mathrm{NMR}(\mathrm{ppm}): 52.74$, 67.16, 75.09, 77.14, 126.92, 127.65, 130.16, 142.39, 172.73. IR $\left(\mathrm{KBr}, \mathrm{cm}^{-1}\right): 3270$, 2126, 1808, 1735. Anal. Calcd for $\mathrm{C}_{23} \mathrm{H}_{18} \mathrm{O}_{2}$ (326.4): C, 84.64; H, 5.56. Found: $\mathrm{C}$, $84.80 ; \mathrm{H}, 5.51$.

\section{Polymerization}

Polymerizations were carried out under an argon atmosphere in a Schlenk tube equipped with a three-way stopcock. A typical procedure is as follows: The monomer solution was prepared in a Schlenk tube by mixing a monomer and a solvent under the conditions described in footnotes of Tables. Another Schlenk tube was charged with a main catalyst, a cocatalyst, and the solvent. The catalyst solution was aged at $60{ }^{\circ} \mathrm{C}$ (for Mo and $\mathrm{W}$ catalysts) for $10 \mathrm{~min}$. In the case of Rh catalysts, the catalyst solution was used without the aging process. Then the monomer solution was added to the catalyst solution, and polymerization was carried out for a given time at a given temperature. Polymer was precipitated in a large amount of methanol, filtered, and dried in vacuum overnight. The yield of the polymer was determined by gravimetry.

\section{Spectroscopic Data of the Polymers}

In the following ${ }^{1} \mathrm{H}$ NMR data, all peaks except for those with descriptions have broad singlet shape.

Poly(1) IR $\left(\mathrm{CHCl}_{3}, \mathrm{~cm}^{-1}\right): 2967,2932,2871,1738,1164,993 .{ }^{1} \mathrm{H}$ NMR (ppm): 0.86 $\left(-\mathrm{CH}_{3}, 3 \mathrm{H}\right), 1.27\left(-\left(\mathrm{CH}_{2}\right)_{2}-\mathrm{CH}_{3}, 4 \mathrm{H}\right), 1.56\left(-\mathrm{CH}_{2}-\left(\mathrm{CH}_{2}\right)_{2}-\mathrm{CH}_{3}, 2 \mathrm{H}\right), 2.27\left(\mathrm{O}_{2} \mathrm{C}-\mathrm{CH}_{2}-\right.$ $\left.\mathrm{CH}_{2}, 2 \mathrm{H}\right), 4.69\left(-\mathrm{HC}=\mathrm{C}-\mathrm{CH}_{2}-, 2 \mathrm{H}\right), 6.25(-\mathrm{HC}=\mathrm{C}-, 1 \mathrm{H})$. Poly $(2)$ IR $\left(\mathrm{KBr}, \mathrm{cm}^{-1}\right)$ : 
2942, 1737, 1375, 1233, 1028, 604. ${ }^{1} \mathrm{H}$ NMR $(\mathrm{ppm}): 2.03\left(-\mathrm{CH}_{3}, 3 \mathrm{H}\right), 4.59(-\mathrm{HC}=\mathrm{C}-$ $\left.\mathrm{CH}_{2}-, 2 \mathrm{H}\right), 6.26(-\mathrm{HC}=\mathrm{C}-, 1 \mathrm{H}) . \operatorname{Poly}(3) \mathrm{IR}\left(\mathrm{KBr}, \mathrm{cm}^{-1}\right): 2981,2931,1735,1218$, 1154. ${ }^{1} \mathrm{H}$ NMR (ppm): 1.81 (br d, $\left.-\mathrm{CH}_{3}, 3 \mathrm{H}\right), 4.43$ (br q, $\left.-\mathrm{CHBr}-, 1 \mathrm{H}\right), 4.81$ $\left(-\mathrm{HC}=\mathrm{C}-\mathrm{CH}_{2}-, 2 \mathrm{H}\right), 6.41 \quad(-\mathrm{HC}=\mathrm{C}-, 1 \mathrm{H}) . \operatorname{Poly}(4)$ IR $\left(\mathrm{KBr}, \mathrm{cm}^{-1}\right): 3062,2946$, 1720, 1268, 1108, 708, 686. ${ }^{1} \mathrm{H}$ NMR $(\mathrm{ppm}): 4.78\left(-\mathrm{HC}=\mathrm{C}-\mathrm{CH} H_{2}-, 2 \mathrm{H}\right), 6.44$ $(-\mathrm{HC}=\mathrm{C}-, 1 \mathrm{H}), 7.12-8.10$ (br m, aromatic H, 5H). Poly (5) IR $\left(\mathrm{KBr}, \mathrm{cm}^{-1}\right): 3057$, $3022,1731,1492,1446,1170,699$. Due to poor solubility, ${ }^{1} \mathrm{H}$ NMR of poly $(\mathbf{5})$ was not measured.

\section{Results and discussion}

\section{Polymerization}

Table 1 lists the results of the polymerization of $\mathbf{1}$ by using Mo, $\mathrm{W}$ and $\mathrm{Rh}$ catalysts. Group 6 transition metal chlorides, $\mathrm{WCl}_{6}$ and $\mathrm{MoCl}_{5}$, in combination with alkylating agents $\left(\mathrm{Ph}_{4} \mathrm{Sn}\right.$ and $\left.n-\mathrm{Bu}_{4} \mathrm{Sn}\right)$ serve as active catalysts in the metathesis polymerization of relatively polar monosubstituted acetylenes [15]. Thus, $\mathrm{WCl}_{6} / \mathrm{Ph}_{4} \mathrm{Sn}$ and $\mathrm{MoCl}_{5} / n$ $\mathrm{Bu}_{4} \mathrm{Sn}$ were used as catalysts to polymerize monomer $\mathbf{1}$ in toluene at $30{ }^{\circ} \mathrm{C}$, but no polymeric products were obtained even after $24 \mathrm{~h}$. Polymerization did not take place in dioxane, either, even at a higher temperature of $60{ }^{\circ} \mathrm{C}$. These results are possibly due to the poisoning interactions of the ester group with the transition metal compounds. In contrast, a frequently used catalyst for the polymerization of polar monosubstituted acetylenes, $\left[(\mathrm{nbd}) \mathrm{RhCl} / \mathrm{Et}_{3} \mathrm{~N}\right.$, resulted in the formation of a polymer with a number-average molecular weight $\left(M_{\mathrm{n}}\right)$ of 20,000 in $64 \%$ yield (Run 4$)$. Under the same conditions, (nbd) $\mathrm{Rh}^{+}\left(\eta^{6}-\mathrm{Ph}^{-} \mathrm{B}^{-} \mathrm{Ph}_{3}\right)$ also afforded a polymer in a similar way (Run 6). The highest polymer yield (77\%) was accomplished when polymerization was conducted at a monomer concentration of $2.0 \mathrm{M}$, where the $M_{\mathrm{n}}$ of polymer was 17,000 (Run 7). The polymerization at $0{ }^{\circ} \mathrm{C}$ gave a high molecular weight $\left(M_{\mathrm{n}}=\right.$ $40,000)$ polymer in a moderate yield $(50 \%)$, whereas the polymer formed at $80{ }^{\circ} \mathrm{C}$ possessed a rather low molecular weight $\left(M_{\mathrm{n}}=9,100\right)$ (Run 8,9$)$. This is possibly due to the instability of the active species and/or chain termination reactions at high temperature. Further increment of the monomer concentration to $3.0 \mathrm{M}$ significantly decreased the $M_{\mathrm{n}}$ from 17,000 to 4,900 (Run 10).

Table 2 shows the result of solvent effects on the polymerization of $\mathbf{1}$ with (nbd) $\mathrm{Rh}^{+}\left(\eta^{6}-\mathrm{Ph}-\mathrm{B}^{-} \mathrm{Ph}_{3}\right)$ at $30{ }^{\circ} \mathrm{C}$. THF was a favorable polymerization solvent with respect to both polymer yield and molecular weight. Toluene, $\mathrm{CH}_{2} \mathrm{Cl}_{2}$ and $\mathrm{CHCl}_{3}$ also worked as useful polymerization solvents, although polymer yield as well as molecular weight more or less decreased. In contrast, anisole and dioxane were not suitable solvents because the molecular weights of polymers were low with broad molecular weight distributions. The use of dimethyl sulfoxide (DMSO) and $N, N$ dimethylformamide (DMF) as polymerization solvents produced poly(1)s with high molecular weights $\left(M_{\mathrm{n}}=21,000-23,000\right)$ in high yields $(79-91 \%)$, although the molecular weight distributions were rather broad $\left(M_{\mathrm{w}} / M_{\mathrm{n}}=5.4-8.2\right)$. On the other hand, the polymerization did not proceed in $\mathrm{CH}_{3} \mathrm{CN}$.

The polymerization of monomers $\mathbf{2}-\mathbf{5}$ was examined by using the zwitterionic catalyst in THF (Table 3). In all cases, polymers were obtained in moderate yields (55-62\%). 


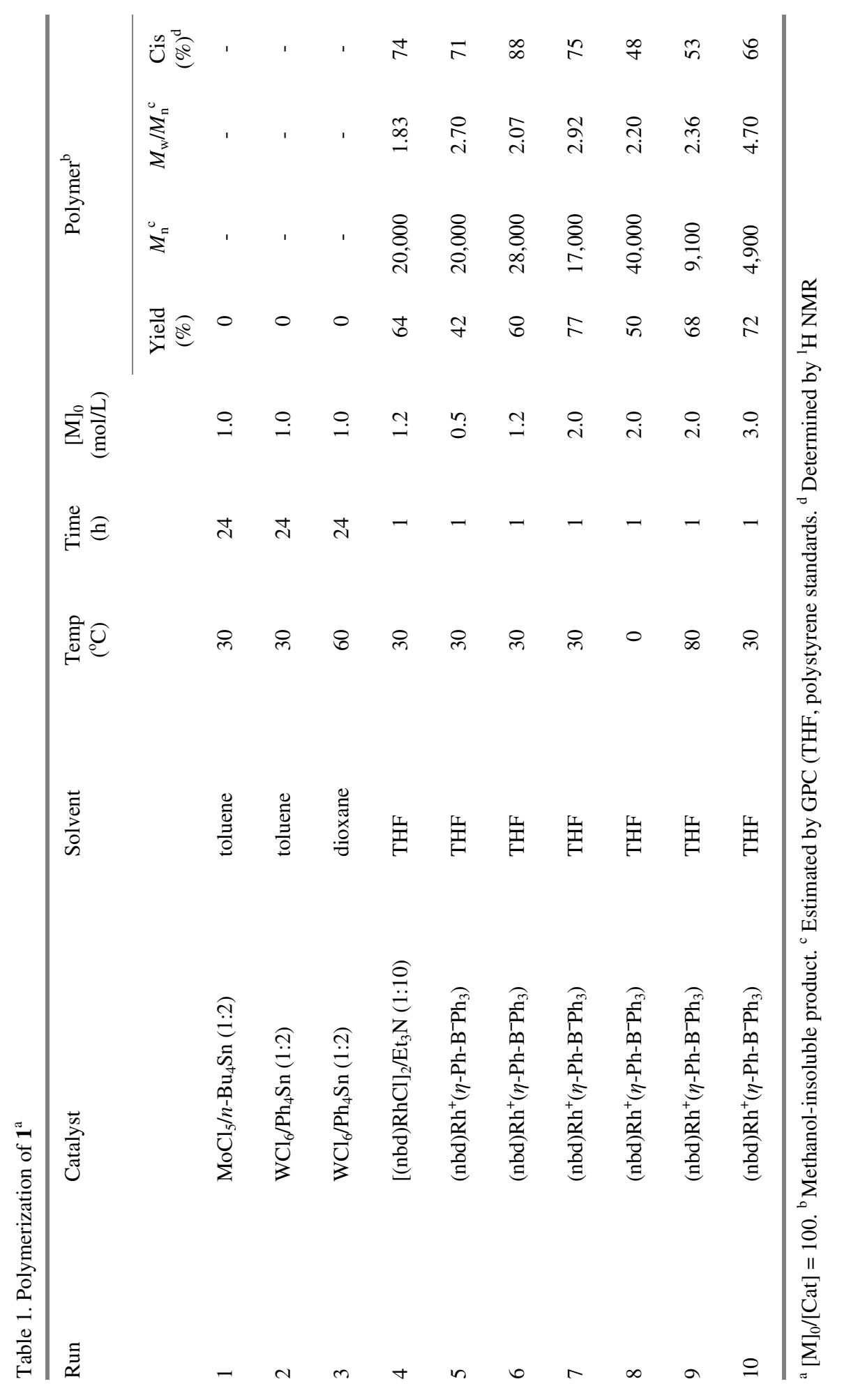


While the $M_{\mathrm{n}}$ of poly(2) and poly(3) were no more than 5,100 and 5,000, respectively, poly $(4)$ had a higher molecular weight $\left(M_{\mathrm{n}}=26,000\right)$. Although monomer 5 was completely soluble in THF, the resulting yellow polymer precipitated out during polymerization in THF; the polymer was insoluble in any organic solvents.

Table 2. Solvent effects on the polymerizations of $\mathbf{1}$ by $(\mathrm{nbd}) \mathrm{Rh}^{+}\left(\eta^{6}-\mathrm{Ph}^{-\mathrm{B}^{-}} \mathrm{Ph}_{3}\right)^{\mathrm{a}}$

\begin{tabular}{llcccc}
\hline \multirow{2}{*}{ Run } & Solvent & \multicolumn{5}{c}{ Polymer $^{\mathrm{b}}$} \\
\cline { 3 - 6 } 1 & THF & $\begin{array}{c}\text { Yield } \\
(\%)\end{array}$ & $M_{\mathrm{n}}{ }^{\mathrm{c}}$ & $M_{\mathrm{w}} / M_{\mathrm{n}}^{\mathrm{c}}$ & $\begin{array}{c}\mathrm{Cis}^{\mathrm{d}} \\
(\%)\end{array}$ \\
2 & toluene & 77 & 17,000 & 2.92 & 75 \\
3 & $\mathrm{CH}_{2} \mathrm{Cl}_{2}$ & 41 & 10,000 & 3.70 & 32 \\
4 & $\mathrm{CHCl}_{3}$ & 51 & 10,000 & 3.78 & 55 \\
5 & anisole & 89 & 10,000 & 11.0 & 50 \\
6 & dioxane & 83 & 6,500 & 12.4 & 45 \\
7 & DMSO & 91 & 21,000 & 5.43 & $-{ }^{\mathrm{e}}$ \\
8 & DMF & 79 & 23,000 & 8.23 & 46 \\
9 & $\mathrm{CH}{ }_{3} \mathrm{CN}$ & 0 & - & - & 58 \\
\hline
\end{tabular}

${ }^{\mathrm{a}}$ Polymerized at $30{ }^{\circ} \mathrm{C}$ for $1 \mathrm{~h} .[\mathrm{M}]_{0}=2.0 \mathrm{M},[\mathrm{M}]_{0} /[\mathrm{Rh}]=100 .{ }^{\mathrm{b}}$ Methanol-insoluble product. ${ }^{\mathrm{c}}$ Estimated by GPC (THF, polystyrene standards). ${ }^{\mathrm{d}}$ Determined by ${ }^{1} \mathrm{H}$ NMR. ${ }^{\mathrm{e}}$ Determination of the cis content was difficult for this sample because of the broad cis peak.

Table 3. Polymerization of $\mathbf{2}-\mathbf{5}$ by $(\mathrm{nbd}) \mathrm{Rh}^{+}\left(\eta^{6}-\mathrm{Ph}^{-\mathrm{B}^{-}} \mathrm{Ph}_{3}\right)^{\mathrm{a}}$

\begin{tabular}{ccccc}
\hline \multirow{2}{*}{ Monomer } & \multicolumn{3}{c}{ Polymer $^{\mathrm{b}}$} \\
\cline { 2 - 5 } & $\begin{array}{c}\text { Yield } \\
(\%)\end{array}$ & $M_{\mathrm{n}}{ }^{\mathrm{c}}$ & $M_{\mathrm{w}} / M_{\mathrm{n}}{ }^{\mathrm{c}}$ & $\begin{array}{c}\text { Cis }^{\mathrm{d}} \\
(\%)\end{array}$ \\
2 & 62 & $5,100^{\mathrm{e}}$ & $11.8^{\mathrm{e}}$ & 71 \\
3 & 55 & 5,000 & 3.10 & 71 \\
4 & 56 & 26,000 & 4.82 & 49 \\
5 & 60 & $-\mathrm{g}$ & $-\mathrm{g}$ & $-\mathrm{g}$ \\
\hline
\end{tabular}

${ }^{\mathrm{a}}$ Polymerized in THF at $30{ }^{\circ} \mathrm{C}$ for $1 \mathrm{~h},[\mathrm{M}]_{0}=2.0 \mathrm{M},[\mathrm{M}]_{0} /[\mathrm{Rh}]=100 .{ }^{\mathrm{b}}$ Methanol-insoluble product. ${ }^{\mathrm{c}}$ Estimated by GPC (THF, polystyrene standards). ${ }^{\mathrm{d}}$ Determined by ${ }^{1} \mathrm{H}$ NMR.

${ }^{\mathrm{e}}$ Estimated by GPC $\left(\mathrm{CHCl}_{3}\right.$, polystyrene standards). ${ }^{\mathrm{g}}$ Insoluble in common solvents.

\section{Polymer Structure}

The structure of the polymers was elucidated by ${ }^{1} \mathrm{H}$ NMR and IR spectroscopies, and all the polymers gave satisfactory spectroscopic data corresponding to their expected molecular structures. IR spectra of monomer $\mathbf{1}$ and poly(1) are given as an example in Figure 1. Monomer 1 exhibits characteristic $\equiv \mathrm{C}-\mathrm{H}$ and $\mathrm{C} \equiv \mathrm{C}$ stretching vibrations at 3295 and $2129 \mathrm{~cm}^{-1}$, respectively, which completely disappear in the spectrum of 


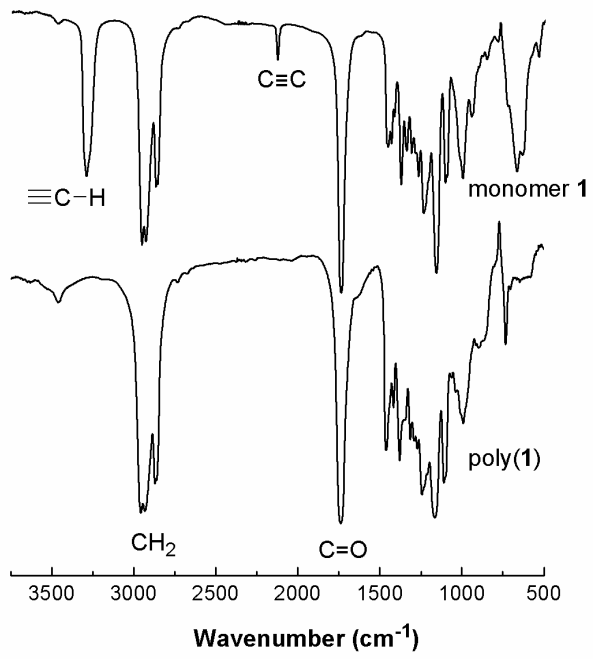

Figure 1. IR spectra of monomer 1 and poly(1) ( $\mathrm{KBr}$ method; poly(1) sample from run 7, Table 1).

poly(1), indicating that the acetylene triple bond of $\mathbf{1}$ has been completely consumed by the polymerization reaction.

In the ${ }^{1} \mathrm{H}$ NMR spectrum of poly(1), the peak due to acetylenic proton of $\mathbf{1}$ at 2.53 ppm completely disappeared and a new resonance peak assignable to the cis olefinic

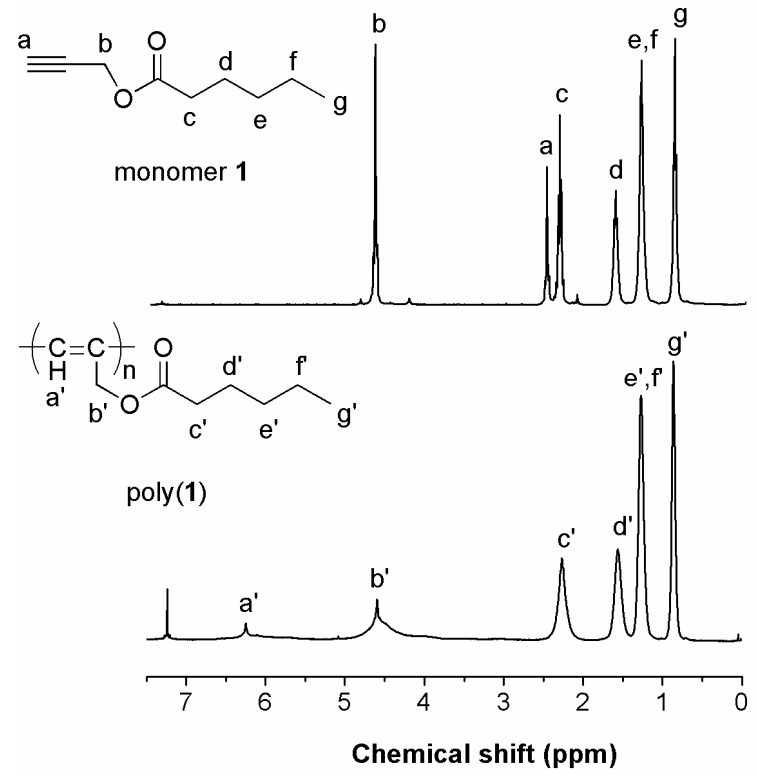

Figure 2. ${ }^{1} \mathrm{H}$ NMR spectra of monomer 1 and poly(1) (measured in $\mathrm{CDCl}_{3}$; poly(1) sample from run 7 , Table 1 ). 
proton of polyene main chain appeared at $6.25 \mathrm{ppm}$, suggesting a cis-transoidal structure of the main chain [16]. The cis contents of poly(1)s in Tables 1 and 2 were estimated by the peak area ratio of olefinic protons of the main chain to methyl group in the pendant $n$-amyl group. It should be noted that the cis contents of poly(propargyl esters) in Tables 1-3 are lower than those (90-100\%) of Rh-catalyzed substituted polyacetylene such as poly(phenylacetylene) [17] and poly(propargyl amides) [18], indicating that the present polymers have less stereoregularity of the polyacetylene backbone than other polymers. The signals characteristic of cis olefinic protons in the range of $6.26-6.44 \mathrm{ppm}$ were also observed in the ${ }^{1} \mathrm{H}$ NMR spectra of poly(2)poly (4). By a method similar to that of poly(1), the cis contents of poly(2)-poly(4) were found to be in the range of $49-71 \%$ (Table 3 ). It has been reported that the peaks of cis protons in the ${ }^{1} \mathrm{H}$ NMR spectrum of poly( $N$-propargylalkylamides $)$ are very broad due to the limited main chain mobility [9]. On the contrary, the ${ }^{1} \mathrm{H}$ NMR spectra of the present poly(propargyl esters) usually showed sharp signals of the cis protons, indicating that their main chain is enough flexible like those of poly(propiolic esters) [19].

\section{Polymer Properties}

Poly(1) was viscous yellow oil owing to the presence of the long alkyl group ( $n$-amyl) along the polymer main chain. Poly $(\mathbf{2})-\operatorname{poly}(\mathbf{5})$ were yellow solids. Figure 3 depicts the UV-vis spectra of poly(1)-poly(4). All the polymers exhibit absorptions in the range from $300 \mathrm{~nm}$ to $425 \mathrm{~nm}$ at longer wavelength region than their corresponding monomers. These absorptions are attributed to the conjugation of the main chain. The absorption of poly $(2)$ is obviously located at shorter wavelengths than those of the other polymers, suggesting that the former has a shorter conjugation length than those of the latter. In the case of poly(4), the absorption peak at $256 \mathrm{~nm}$ in the ultraviolet region is associated with the pendant phenyl group.

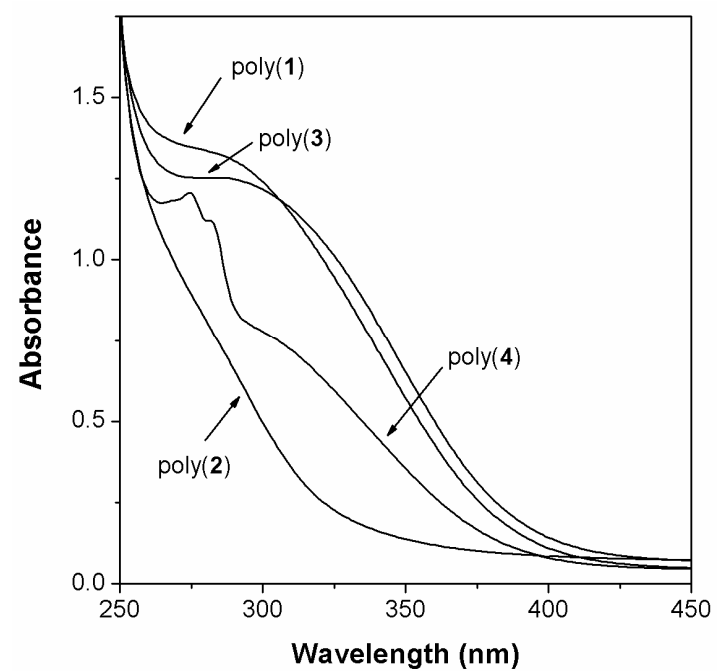

Figure 3. UV-vis spectra of poly(1)-poly(4) in $\mathrm{CHCl}_{3}$ (concentration: $0.075 \mathrm{mg} / \mathrm{mL}$; poly (1) from run 7 , Table 1). 
$\operatorname{Poly}(\mathbf{1})$, poly(3) and $\operatorname{poly}(4)$ were completely soluble in common organic solvents such as toluene, THF and $\mathrm{CHCl}_{3}$. Poly(2) was soluble in toluene and $\mathrm{CHCl}_{3}$ but was insoluble in THF. Poly (5) was insoluble in common organic solvents, presumably owing to the bulky triphenylmethyl pendant group. The thermal stability of poly(1)poly(5) was evaluated by the thermogravimetric analysis (TGA) (Figure 4). All the polymers started to lose weight from 150 to $200{ }^{\circ} \mathrm{C}$. The temperatures for $5 \%$ weight loss in poly(4) and poly(5) were higher than those of $\operatorname{poly}(\mathbf{1})-\operatorname{poly}(\mathbf{3})$, which shows that aromatic substituents impart thermal stability to the polymers. The temperature for $5 \%$ weight loss in poly $(4)$ is around $250{ }^{\circ} \mathrm{C}$, which is slightly higher than that of poly(phenylacetylene) $\left(225^{\circ} \mathrm{C}\right)[20]$.

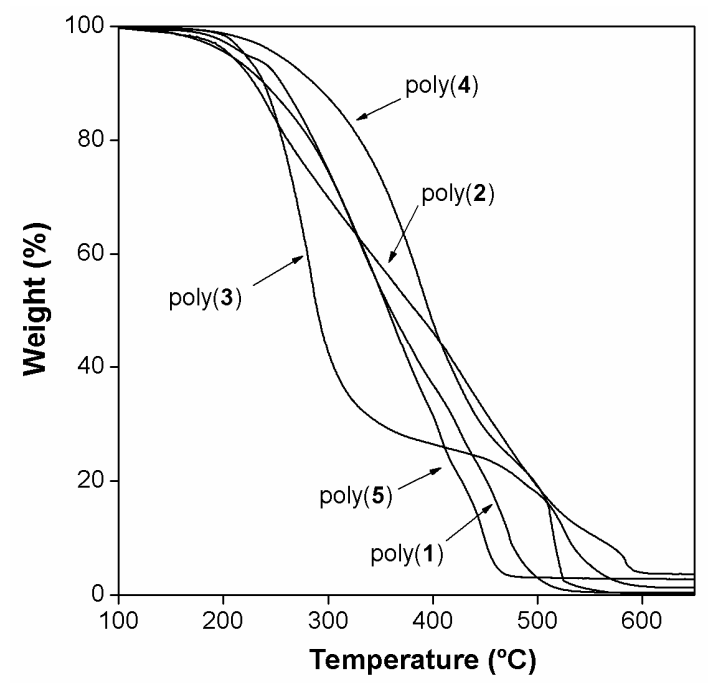

Figure 4. TGA curves of poly $(\mathbf{1})-\operatorname{poly}(\mathbf{5})$ (measured in air; heating rate: $10{ }^{\circ} \mathrm{C} / \mathrm{min}$; poly (1) from run 7 , Table 1).

\section{Conclusions}

Polymerization of propargyl esters $(\mathbf{1 - 5})$ in the presence of Rh catalysts afforded the corresponding polymers, poly(1)-poly(5), with $M_{\mathrm{n}}=4,900-40,000$. $\operatorname{Poly}(\mathbf{1}), \operatorname{poly}(\mathbf{3})$ and poly(4) were readily soluble in common organic solvents such as toluene, THF and $\mathrm{CHCl}_{3}$, and poly(2) showed similar solubility property but was insoluble in THF. The ${ }^{1} \mathrm{H}$ NMR spectra of the formed polymers exhibited signals in the range of 6.25$6.44 \mathrm{ppm}$ assignable to the cis olefinic proton of polyacetylene main chain, indicating the cis-transoidal main-chain structure. The UV-vis spectra of poly(1)-poly(4) displayed absorptions in the region of $300-425 \mathrm{~nm}$, which are attributed to the conjugation of the main chain.

\section{References}

1. Masuda T, Sanda F (2003) Handbook of Metathesis Vol. 3. Grubbs RH (ed) Wiley-VCH, Weinheim (p 375)

2. Lam JWY, Tang BZ (2005) Acc Chem Res 38: 745 
3. Yang MJ, Sun HM, Ling MF (2000) Acta Polym Sinica 2:161

4. Sun HM, Yang MJ, Ling MF (2000) Chin Chem Lett 11:1097

5. Yang MJ, Li Y (2002) Sensors and Actuators, B: chemical B 86:155

6. Lee WC, Sohn JE (1998) Journal of the Korean Fiber Society 25:546

7. Zhan XW, Yang MJ, Sun HM (2001) Macromol Rapid Commun 22:530

8. Li Y, Yang MJ (2004) Chin J Polym Sci 22:485

9. Nomura R, Tabei J, Masuda T (2001) J Am Chem Soc 123:8430

10. Gao GZ, Sanda F, Masuda T (2003) Macromolecules 36:3932

11. Zhang W, Shiotsuki M, Masuda T (2006) Macromol Chem Phys, submitted

12. Schrock RR (1971) J Am Chem Soc 93:2397

13. Schrock RR, Osborn JA (1970) Inorg Chem 9:2339

14. Ott I, Schmidt K, Kircher B, Schumacher P, Wiglenda T, Gust R. (2005) J Med Chem 48:622

15. Masuda T, Higashimura T (1987) Adv Polym Sci 81:121

16. Masuda T (1997) Catalysis in Precision Polymerization. Kobayashi S (ed) Wiley, Chichester (Chapter 2.4)

17. Tabata M, Sone T, Sadahiro Y (1999) Macromol Chem Phys 200:265

18. Tabei J, Nomura R, Masuda T (2003) Macromolecules 36:573

19. Nakako H, Nomura R, Tabata M, Masuda T (1999) Macromolecules 32:2861

20. Masuda T, Tang BZ, Higashimura T, Yamaoka H (1985) Macromolecules 18:2369 